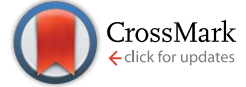

Cite this: RSC Adv., 2017, 7, 6242

\title{
Gas-phase conformational preference of the smallest saccharide (glycolaldehyde) and its hydrated complexes with bridged hydrogen bondingt
}

\begin{abstract}
Pengchao Wang, Yongjun Hu, ${ }^{*}$ Huaqi Zhan and Jiaxin Chen
Glycoaldehyde $\left(\mathrm{GA}, \mathrm{HOCH}{ }_{2} \mathrm{CHO}\right)$ is the simplest sugar unit of the carbohydrates and the only sugar to have been detected in interstellar space to date. In the present report, the conformation of GA and its flexible hydrated complexes have been investigated in the gas phase by using mass-selected infrared (IR) spectroscopy based on vacuum-ultraviolet single photon ionization (118 nm). With the aid of theoretical calculations, the neutral GA bearing a ring-type intramolecular hydrogen bonding interaction was confirmed to be the dominant isomer in the gas phase. Moreover, the water molecules in the monohydrated complexes preferentially broke the intramolecular hydrogen bond and bridged the carbonyl oxygen and hydroxyl hydrogen of GA with two additional intermolecular $\mathrm{H}$-bonds, revealing the "working rules" governing preferred binding. The theoretical results confirmed that the existence probability of the two lowest energy conformations stabilized by two intermolecular hydrogen bonds would be larger than that of the next two isomers with one intramolecular plus one intermolecular hydrogen bond. Structural investigation of hydrated GA conformers has revealed that the water molecules play the role of a bridge through intermolecular $\mathrm{H}$-bonds, achieving selective population of specific GA molecular conformations. These results suggest that these hydrogen-bonded bridge structures in the hydrated complexes may provide good models for recognition in larger systems.
\end{abstract}

Received 18th November 2016 Accepted 10th January 2017

DOI: 10.1039/c6ra26965f

www.rsc.org/advances changing the preferred monomeric conformation of the hydroxymethyl group from gg to gt. ${ }^{13}$ However, it is unclear how the inserted water alters the conformation of the substrate and what governs the preferred binding sites in those hydrated carbohydrate complexes that do not contain a phenyl chromophore.

GA is the simplest sugar unit of the carbohydrates and the only sugar to have been detected in interstellar space to date. ${ }^{14-16}$ Water, the most ubiquitous and fundamental solvent on earth, is a critical component in many physical and chemical processes in chemistry, biology, and geochemistry. ${ }^{17,18} \mathrm{~A}$ molecular-level understanding of the role of water as an active participant in this simplest sugar molecules is, therefore, of significant interest. More specifically, it's intriguing to understand why the water opts to locate close to the hydroxyl or carbonyl group in the GA-water complex. In this case, the molecules form a complex while maintaining the intramolecular hydrogen bonds, e.g., via stacking, or the intramolecular bonds are broken for the sake of intermolecular hydrogen bonding, or some intermediate form.

An alternative approach to studying the interaction of molecules is to prepare jet-cooled neutral molecular aggregates in the gas phase. ${ }^{19}$ These neutral molecules can be subjected to size- and state-specific spectroscopic investigations without
MOE Key Laboratory of Laser Life Science \& Institute of Laser Life Science, College of Biophotonics, South China Normal University, Guangzhou 510631, P. R. China. E-mail: yjhu@scnu.edu.cn; Fax: +86-20-85216052; Tel: +86-20-85217070

$\dagger$ Electronic supplementary information (ESI) available. See DOI: 10.1039/c6ra26965f 
suffering thermal effects and perturbations from their surrounding environment. ${ }^{20}$ Resonance-enhanced multiphoton ionization (REMPI) is a powerful technique with a wide range of potential applications, including double resonance IR-UV. ${ }^{21}$ However, these applications require the presence of a ultraviolet (UV) chromophore in the molecule and a sufficiently long-lived resonant intermediate electronic state, to allow for effective detection and monitor. ${ }^{22}$ These techniques are, therefore, inapplicable for unperturbed detection of species without a UV chromophore group. One way of circumventing this limitation is to use single photon ionization in the vacuum-ultraviolet (VUV) region, which has the advantage to detect aliphatic molecules. The recent development of vibrational spectroscopic techniques based on VUV photoionization and its subsequent combination with supersonic-jet expansion techniques (typically pulsed jets) have made it possible to observe the IR spectra of simple and fundamental molecular aggregates in their neutral states. ${ }^{23,24}$ This effective approach can provide the information of the geometric structures of molecules, clusters and their intermolecular interactions. ${ }^{19,25-29}$ Furthermore, the vibrational frequencies and intensities of IR absorption, such as modes involving $\mathrm{OH}, \mathrm{NH}$, and $\mathrm{CH}$ groups, are generally very sensitive probes of hydrogen bonding and other intra- and inter-molecular interactions, which make them excellent probes for investigation of detailed aspects of the structures of biologically relevant ions, radicals, and molecules. ${ }^{23}$

The structure of GA determined by intramolecular hydrogen bonding interaction was previously detected by conventional IR and Raman spectroscopy in the gas phase or in matrix isolation. ${ }^{30-32}$ The GA-water complex was studied by Fourier transform microwave spectroscopy, where only two lowest conformers referring to cis-cis-water-1 (CC-W-1) and cis-ciswater-2 (CC-W-2) conformer could be found in the gas phase. ${ }^{33}$ To comprehensively consider the existence of these conformers under isolated conditions without thermal effects and perturbations from their surrounding environment, mass selected optical spectroscopy, as a powerful method, was used herein to investigate gas-phase GA molecules and their hydrated complexes in a supersonic jet. It is worthy of further discussion for the more detailed information about structures of GA molecule compared with its hydrated complexes in the gas phase. Herein, we present direct evidence for the dominant conformer of neutral GA in the gas phase based on the results of IR plus VUV (118 nm) single photon ionization spectroscopy and density functional theory (DFT) calculations. Moreover, the role of water in the formation of monohydrated complex GAwater conformations in the gas phase is discussed.

\section{Experimental setup and calculation methods}

\subsection{Experimental setup}

IR spectra of neutral GA and GA-water were recorded based on the VUV photoionization detection. The experimental equipment was set up by our group and its details have been described elsewhere, ${ }^{34-38}$ and only a brief description is given here. A gaseous mixture of sample molecules and helium was expanded supersonically into the vacuum system through a pulsed valve (Parker General Valve series 9) with a pulse width of ca. $150 \mu \mathrm{m}$ duration. Passing through a skimmer, the molecular beam interacted with pulsed IR and VUV light ( $c a .10$ ns) in the ionization region of the time-of-flight mass spectrometry (TOFMS), which is used for the detection of the generated ions. The TOFMS has been set to maximize the intensity of the higher masses by optimizing the time delay between the nozzle opening and the VUV laser triggering. GA and water were purchased from Aladdin-Reagent Company (Shanghai, China) and used without additional purification.

The $118 \mathrm{~nm}$ VUV light is the ninth harmonic of the $1.064 \mu \mathrm{m}$ fundamental radiation of a $\mathrm{Nd}^{3+} / \mathrm{YAG}$ laser. The $355 \mathrm{~nm}$ radiation from an Nd/YAG laser (third harmonic) is focused into a cell containing a Xe/Ar $1: 10$ mixture at 200 Torr total pressure. $\mathrm{An} \mathrm{MgF}_{2}$ lens focuses the $118 \mathrm{~nm}$ light in the ionization region of the TOFMS and disperses the remaining $355 \mathrm{~nm}$ light. Tunable IR radiation output in the mid-IR range has a pulse energy of 3-5 mJ per pulse (2650-3850 $\left.\mathrm{cm}^{-1}\right)$, a time duration of ca. $10 \mathrm{~ns}$, and a bandwidth of $c a .2 \mathrm{~cm}^{-1}$.

The principle of IR plus VUV non-resonant ionization has been described previously. ${ }^{23}$ IR spectra of neutral monomer and its hydrated complexes were observed by size-selective IR spectroscopy with the VUV photoionization detection schemes, which are called the Non-Resonant Ion Dip IR Spectroscopy (NRIDip-IR). The IR pulse was introduced ca. $30 \mathrm{~ns}$ prior to the VUV ionization for spectroscopy of neutrals. Note that the VUV (non-resonant) photon energy (ca. $10.49 \mathrm{eV}$ ) is $0.29 \mathrm{eV}$ above the ionization energy (IE) $(\mathrm{GA}=10.20 \mathrm{eV})$ of the GA monomer. ${ }^{39}$ To measure the IR spectrum, the mass-selected ion intensity was monitored while the IR frequency was scanned. In the present measurements, IR spectra of sample molecules were obtained by monitoring their parent channels. The concentrations of sample molecules were controlled in order to prevent the formation of large cluster in the jet expansion.

\subsection{Calculation methods}

All the following theoretical calculations of the monomer and its hydrated complexes were performed with the GAUSSIAN 03 and GAUSSIAN 09 program packages. ${ }^{\mathbf{4 0 , 4 1}}$ Geometry optimization of neutral molecules were calculated by the DFT and MP2 functional. The MP2 theoretical functional, which accounts for the electron correlation, can obtain more reliable results for correlation energies than the DFT method. ${ }^{42}$ Therefore, the geometry optimization and correlation energies of GA and GAwater were predicted by MP2/6-311++G(d,p). The $\omega$ B97X-D functional contains the empirical treatment of dispersion interactions and gives reliable non-covalent interactions for many systems, i.e., dimethyl ether dimer, tryptamine ${ }^{+}-\left(\mathrm{N}_{2}\right)_{n}$ and their hydrated complexes with satisfactory vibrational frequencies. ${ }^{4-47}$ Thus, the dispersion-corrected density functional theory calculations were performed at the unrestricted $\omega \mathrm{B} 97 \mathrm{X}-\mathrm{D} / \mathrm{cc}-\mathrm{pVTZ}$ level to obtain vibrational energy of the GA and its hydrated complexes. The harmonic frequencies are scaled by a factor of $0.9415 .^{43,44}$ For the hydrated complexes, 
natural bond orbital (NBO) analysis was also employed with the $\omega$ B97X-D functional and cc-pVTZ basis set. ${ }^{48}$ All relative energies were zero-point energy (ZPE)-corrected in the Gaussian program..$^{40,41}$ The optimized structures and NBO diagrams were visualized using the GaussView 5 program.

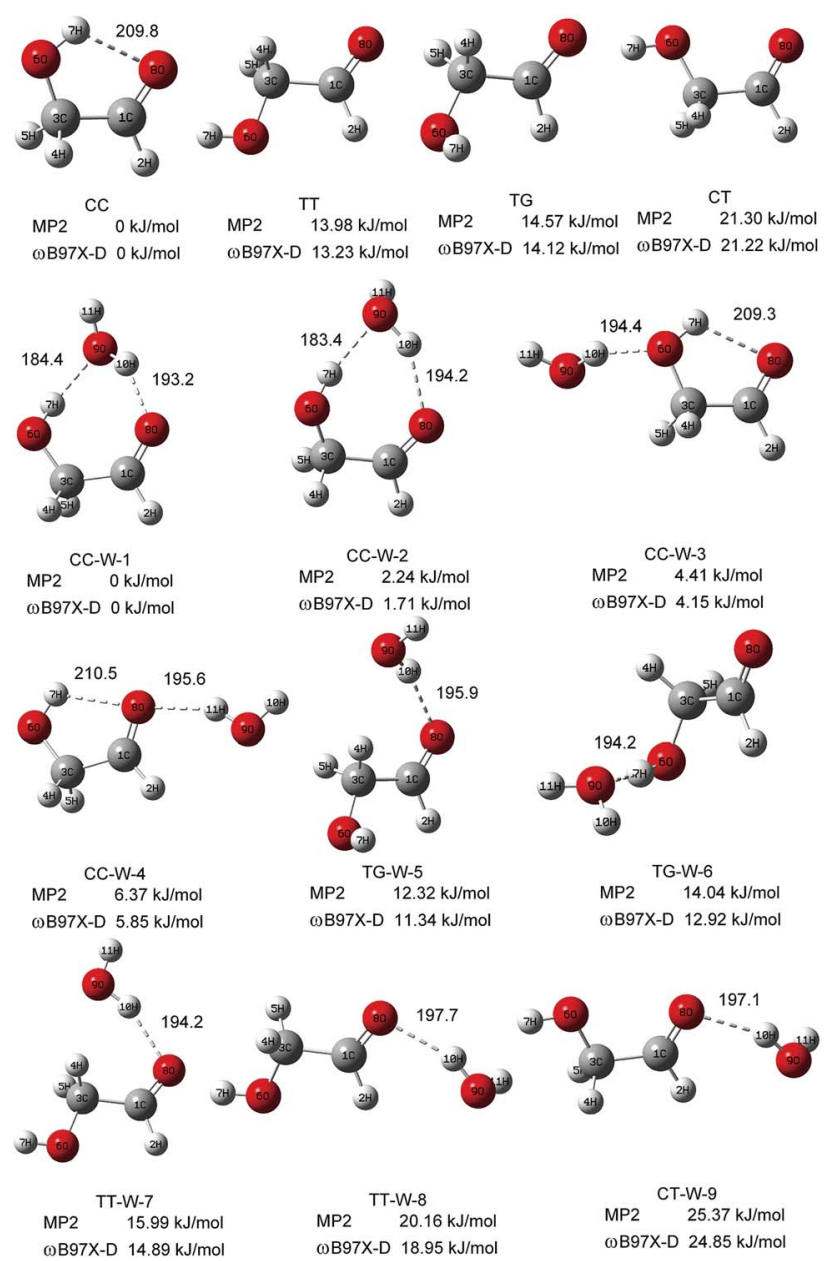

Fig. 1 The stable structures and calculated relative energy of the GA and GA-water conformers at the $\omega B$ B7X-D/cc-pVTZ and MP2/6$311+G(d, p)$ levels. The bond lengths are in picometers.

\section{Results and discussion}

\subsection{Theoretical calculations about geometric parameters of glycolaldehyde and glycolaldehyde-water}

Fig. 1 shows the fully optimized geometries of the four most stable conformers of the GA and nine GA-water complex conformers. Compared with MP2/6-311++G(d,p), the conformers are more stable at $\omega$ B97X-D/cc-pVTZ level. So the final computational results were discussed at this level. Based on ab initio results, the simulated GA conformers include cis-cis (CC), trans-trans (TT), trans-gauche (TG) and cis-trans (CT) forms, where CC is the most stable conformer stabilized by an intramolecular $\mathrm{H}$-bond between the hydrogen atom $(7 \mathrm{H})$ of the hydroxyl group and the oxygen atom (8O) from the carbonyl group. The TT (13.23 $\left.\mathrm{kJ} \mathrm{mol}^{-1}\right)$ and TG (14.12 kJ mol ${ }^{-1}$ ) conformers are almost isoenergetic with the TT conformer being slightly lower in energy. The CT $(21.22 \mathrm{~kJ}$ $\mathrm{mol}^{-1}$ ) conformer is the highest in energy of all four GA conformers and differs from $\mathrm{CC}$ by rotation of the $\mathrm{OH}(6 \mathrm{O}-7 \mathrm{H})$ group. Compared with previous calculations, i.e., CC $(0.0 \mathrm{~kJ}$ $\left.\mathrm{mol}^{-1}\right)$, TT (15.21 kJ mol$\left.{ }^{-1}\right)$, TG (15.43 $\left.\mathrm{kJ} \mathrm{mol}^{-1}\right)$ and CT (22.19 kJ $\mathrm{mol}^{-1}$ ), at MP4 (SDTQ)/cc-pVQZ level, our theoretical predicted results are close to their results. ${ }^{49}$

In the nine GA-water complex conformers, water can serve as a hydrogen bond donor for the hydroxyl or carbonyl oxygen of GA, and it can also act as a hydrogen bond acceptor for the $\mathrm{OH}$ group. Their main structural parameters are list in Table 1. It should be noted that the four most stable conformers are associated with the CC conformer of the parent molecule and stabilized by two hydrogen bonds. However, the next five conformers, i.e., trans-gauche-water-5 (CC-W-5, $11.34 \mathrm{~kJ}$ $\mathrm{mol}^{-1}$ ), trans-gauche-water-6 (CC-W-6, $12.92 \mathrm{~kJ} \mathrm{~mol}^{-1}$ ), transtrans-water-7 (CC-W-7, $14.89 \mathrm{~kJ} \mathrm{~mol}^{-1}$ ), trans-trans-water-8 (CC$\mathrm{W}-8,18.95 \mathrm{~kJ} \mathrm{~mol}^{-1}$ ), and cis-trans-water-9 (CC-W-9, $24.85 \mathrm{~kJ}$ $\mathrm{mol}^{-1}$ ), only contain one intramolecular hydrogen bond respectively. In CC-W-1 and CC-W-2 conformers, water broke the intramolecular hydrogen bond and bridged the carbonyl oxygen $(8 \mathrm{O})$ and hydroxyl hydrogen $(7 \mathrm{H})$ of CC by two additional intermolecular $\mathrm{H}$-bonds. It can be found that the structures of the parent molecule in CC-W-1 and CC-W-2 conformers are changed in the $6 \mathrm{O}-7 \mathrm{H}$ group (dihedral angle $1 \mathrm{C}-3 \mathrm{C}-6 \mathrm{O}-7 \mathrm{H}$ changing from $0.0^{\circ}$ to $49.7^{\circ}$ and $48.9^{\circ}$, respectively). However,

Table 1 Geometric parameters of nine stable glycolaldehyde-water complex conformers compared with CC conformer are calculated at the $\omega B 97 X-D / c c-p V T Z$ level

\begin{tabular}{|c|c|c|c|c|c|}
\hline & $\mathrm{CC}$ & CC-W-1 & CC-W-2 & CC-W-3 & CC-W-4 \\
\hline $7 \mathrm{H}-9 \mathrm{O}$ or $7 \mathrm{H}-8 \mathrm{O} / \mathrm{pm}$ & 209.8 & 184.4 & 183.4 & 209.3 & 210.5 \\
\hline $8 \mathrm{H}-10 \mathrm{O}$ or $8 \mathrm{O}-11 \mathrm{H} / \mathrm{pm}$ & & 193.2 & 194.2 & 194.4 & 195.6 \\
\hline 1C-3C-6O-7H/deg & 0.0 & 49.7 & 48.9 & 359.4 & 359.0 \\
\hline $11 \mathrm{H}-9 \mathrm{O}-8 \mathrm{O}-1 \mathrm{C} / \mathrm{deg}$ & & 128.1 & 265.3 & 116.8 & 185.5 \\
\hline $8 \mathrm{H}-10 \mathrm{O} / \mathrm{pm}$ & 195.9 & 194.2 & 194.2 & 197.7 & 197.1 \\
\hline $8 \mathrm{O}-1 \mathrm{C}-3 \mathrm{C}-6 \mathrm{O} / \mathrm{deg}$ & 191.7 & 190.5 & 180.6 & 173.1 & 0.7 \\
\hline $1 \mathrm{C}-3 \mathrm{C}-6 \mathrm{O}-7 \mathrm{H} / \mathrm{deg}$ & 85.9 & 71.2 & 179.9 & 176.1 & 181.2 \\
\hline $11 \mathrm{H}-9 \mathrm{O}-8 \mathrm{O}-1 \mathrm{C} / \mathrm{deg}$ & 130.0 & 79.9 & 175.7 & 102.6 & 108.2 \\
\hline
\end{tabular}


the difference between $\mathrm{CC}-\mathrm{W}-1$ and $\mathrm{CC}-\mathrm{W}-2$ conformers is mainly related to the position of the free $9 \mathrm{O}-11 \mathrm{H}$ water group with respect to $8 \mathrm{O}-1 \mathrm{C}$ (dihedral angle $11 \mathrm{H}-9 \mathrm{O}-8 \mathrm{O}-1 \mathrm{C}$, equal to $128.1^{\circ}$ and $256.3^{\circ}$, respectively). In addition, the free water plays a role of donor in cis-cis-water-3 (CC-W-3) conformer and bond to hydroxyl oxygen (6O) by intermolecular hydrogen

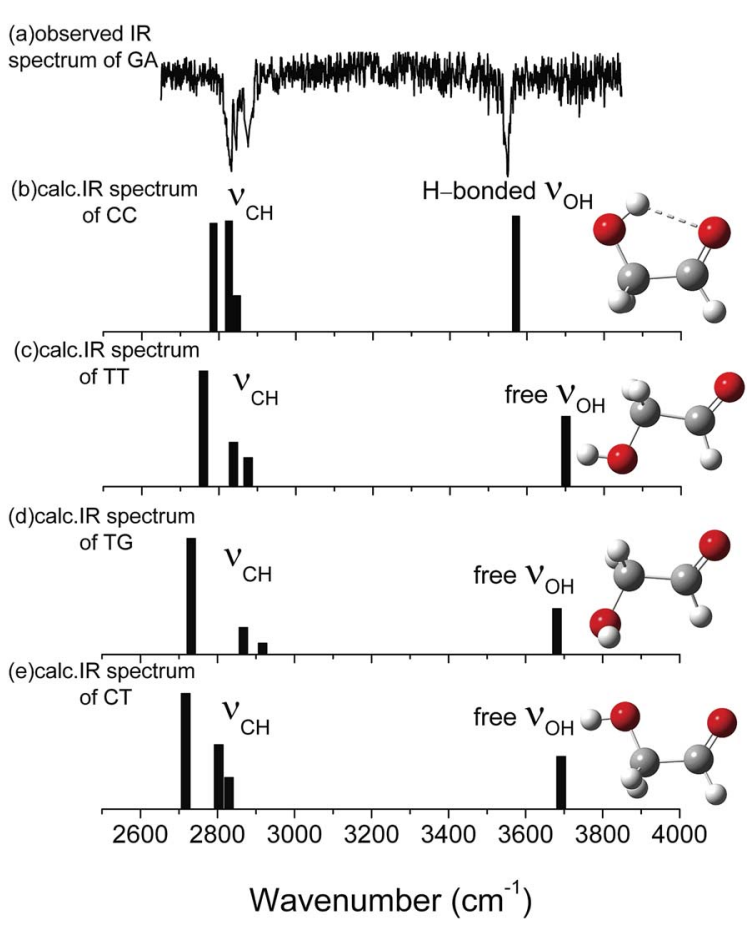

Fig. 2 (a) Observed ir spectra of $\mathrm{HOCH}_{2} \mathrm{CHO}$ and (b)-(e) $\omega \mathrm{B} 97 \mathrm{X}-\mathrm{D} /$ cc-pVTZ calculated stick spectra of the most stable conformers of GA. The sticks represent $\mathrm{OH}$ and $\mathrm{CH}$ stretches. Carbon atoms are in grey, oxygen in red, and hydrogen in white. The calculated vibrational spectra are scaled by 0.9415 . bonding while the water bind to carbonyl oxygen (8O) in cis-ciswater-4 (CC-W-4) conformer. In contrast with the $\mathrm{CC}$ conformer, the most significant features of the four conformers are the reorientation of the $6 \mathrm{O}-7 \mathrm{H}$ hydroxyl group, moving from the plane into the direction of water to form a dihedral angle $(1 \mathrm{C}-3 \mathrm{C}-6 \mathrm{O}-7 \mathrm{H})$ of about $49.7^{\circ}$ in CC-W-1 $\left(48.9^{\circ}\right.$ in CC-W2 ), with a dihedral angle $(1 \mathrm{C}-3 \mathrm{C}-6 \mathrm{O}-7 \mathrm{H})$ of about $359.4^{\circ}$ in CC-W-3 $\left(359.0^{\circ}\right.$ in CC-W-4). In the next five high energy conformers, the water serve as a hydrogen bond donor binding to carbonyl oxygen of parent molecule except the TG-W-6 conformer, in which the water acts as a hydrogen bond acceptor.

\subsection{Experimental results}

3.2.1 IR spectra of neutral GA. The observed and calculated IR spectra of neutral GA are shown in Fig. 2, together with the optimized structures of the four stable conformers of neutral GA found in this study. The IR spectrum of neutral GA was measured under the conditions that no cluster larger than the monomer was observed in the mass spectrum. These conditions therefore confirmed that the neutral GA monomer was the carrier species of the spectrum. The experiment spectrum was observed by NRIDip-IR, the principle of which was previously employed in acetone and 2-propanol clusters. ${ }^{50,51}$ When vibrational predissociation of a neutral GA monomer is induced by vibrational excitation with the IR light, the monitored ion intensity decreases. Therefore, by scanning the IR light wavelength, one can observe the IR spectrum of the monomer as a dip spectrum of the monitored monomer ion intensity. Four peaks were observed in this spectrum, which was obtained by monitoring the mass channel for $\mathrm{HOCH}_{2} \mathrm{CHO}^{+}(60)$ when the IR laser wavelength was scanned from 2650 to $3850 \mathrm{~cm}^{-1}$. Fig. 2 shows that only the hydrogen bond $\mathrm{OH}$ stretching band of the global minimum energy CC conformer is consistent with the

Table 2 The experimental value and calculated vibrational transitions $\left(\mathrm{cm}^{-1}\right)$ for the glycolaldehyde in its CC form with the $\omega$ B97X-D/cc-pVTZ level $^{a}$

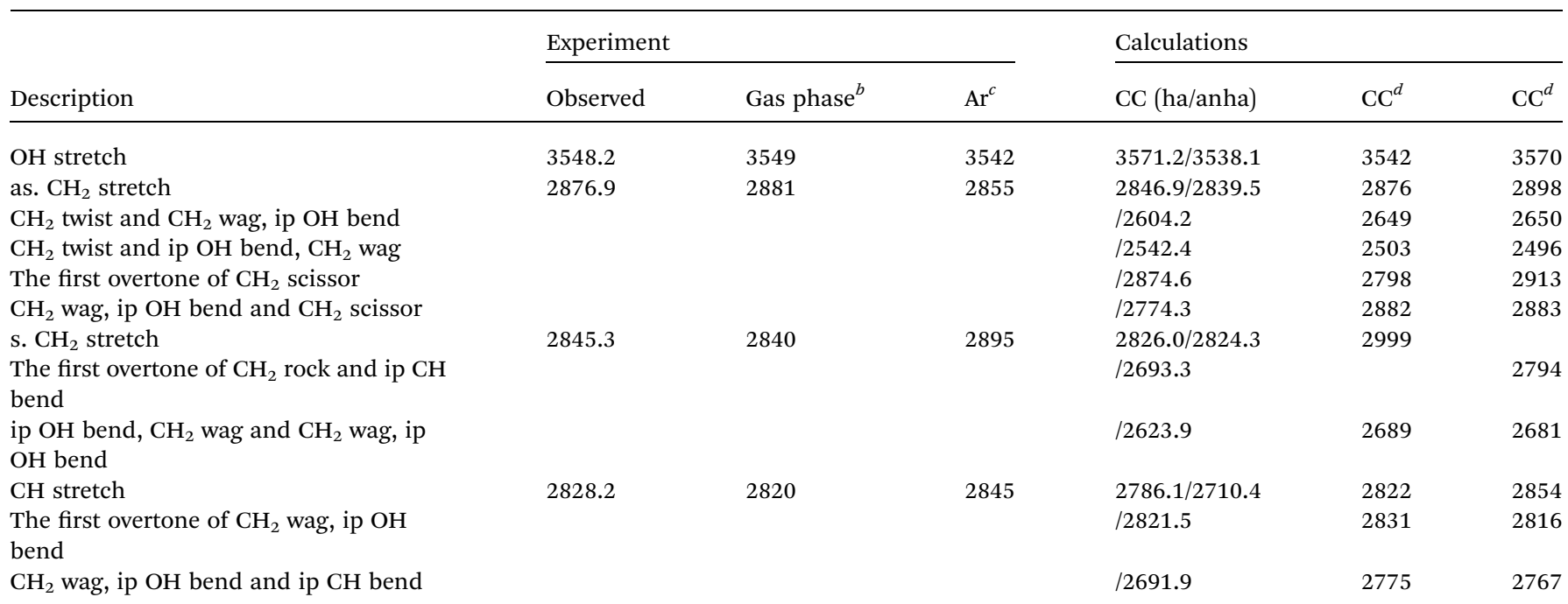

${ }^{a}$ Comparison with the experimental values obtained in gas phase and calculated wavenumbers at MP2/6-311++G(d,p) and CCSD(T)/cc-pVTZ level.

${ }^{b}$ Taken from ref. 52. ${ }^{c}$ Taken from ref. 53. ${ }^{d}$ Taken from ref. 54. 
experimental observed $\mathrm{OH}$ stretching band centered at 3548.2 $\mathrm{cm}^{-1}$. In addition, the calculated $\mathrm{CH}$ bands for the $\mathrm{CC}$ conformer, attributed to the anti-symmetric $\mathrm{CH}_{2}$, symmetric $\mathrm{CH}_{2}$ and $\mathrm{CH}$ stretching vibrations, are consistent with those observed experimentally in the $\mathrm{CH}$ stretch region. These results, therefore, confirm that neutral GA would dominantly exist as the CC conformer in the gas phase with a ring-type intramolecular hydrogen bond interaction between its carbonyl oxygen and the hydrogen atom of its hydroxyl group. Table 2 presents the frequencies of the experimental bands and the vibrational transitions of the calculated $\mathrm{CC}$ form in accord with experimental spectrum. Due to the symmetric $\mathrm{CH}_{2}$ and $\mathrm{CH}$ stretching modes affected by strong anharmonic couplings, several IR-active overtones and combination bands appear in the calculated $\mathrm{CH}$ region. In the region above $2840 \mathrm{~cm}^{-1}$, the experimental transition observed at $3548.2 \mathrm{~cm}^{-1}$ was assigned to $\mathrm{OH}$ stretch while the experimental value at $2876.9 \mathrm{~cm}^{-1}$ corresponds probably to the first overtone of $\mathrm{CH}_{2}$ scissor transition. And the latter assignment is obviously different from previous reports that the first overtone of $\mathrm{CH}_{2}$ scissor transition have little effect on the experimental value. ${ }^{52}$ The theoretical description reveals a more subtle interplay involving two transitions between the symmetric $\mathrm{CH}_{2}$ stretch and $\mathrm{CH}$ stretch, calculated at 2693.3 and $2623.9 \mathrm{~cm}^{-1}$, respectively, which make less influence on the experimental transition. Note that the experimental transition observed at $2828.2 \mathrm{~cm}^{-1}$ corresponds probably to the first overtone of $\mathrm{CH}_{2}$ wag, which is similar to previous assignment. ${ }^{52}$ In addition, anharmonic computations show a rich structure of bands between 2650 and $3000 \mathrm{~cm}^{-1}$, and in particular between 2700 and $2850 \mathrm{~cm}^{-1}$, very loosely reproduced at the harmonic level, due to significant contributions from transitions to combination bands and overtones. The harmonic computations differ less from its anharmonic counterpart in higher energy range. For the harmonic frequencies shown in Table 2, it appears to be in qualitative agreement with respect to the experimental one, with mostly a bandshift. Inclusion of anharmonicity corrects very well the band positions and gets more close to the experiment. Compared with the gas phase IR spectrum recorded at $300 \mathrm{~K}$ and low-temperature experiments in Ar matrix obtained in previous study, ${ }^{53,54}$ the observed frequencies in our work were close to their results, especially in the $\mathrm{OH}$ region. In conclusion, the present analysis confirms the experimental results and are similar to previous results..$^{53,54}$

3.2.2 IR spectra of neutral GA-water. Fig. 3 presents the IR spectra of the neutral GA-water monomer observed by NRIDipIR with single photon soft ionization at $118 \mathrm{~nm} .{ }^{23}$ These spectra were also obtained by monitoring the GA-water monomer cation under the condition that no cluster larger than the GAwater monomer was observed in the mass spectrum. Fig. $3(\mathrm{~b}-\mathrm{j})$ shows the simulated IR spectrum for the stable structure and water-binding sites in each conformer calculated at $\omega \mathrm{B} 97 \mathrm{X}-\mathrm{D} /$ cc-pVTZ level. It is found that the first conformer [Fig. 3(b)] is the most stable isomer (CC-W-1), where the water locates between the carbonyl $(8 \mathrm{O})$ and hydroxyl $(7 \mathrm{H})$ group to form a cyclic H-bond. The isomers CC-W-2 [Fig. 3(c)] and CC-W-1 have similar stretching motions, including one free $\mathrm{O}-\mathrm{H}$ (a) observed IR spectrum of GA-Water

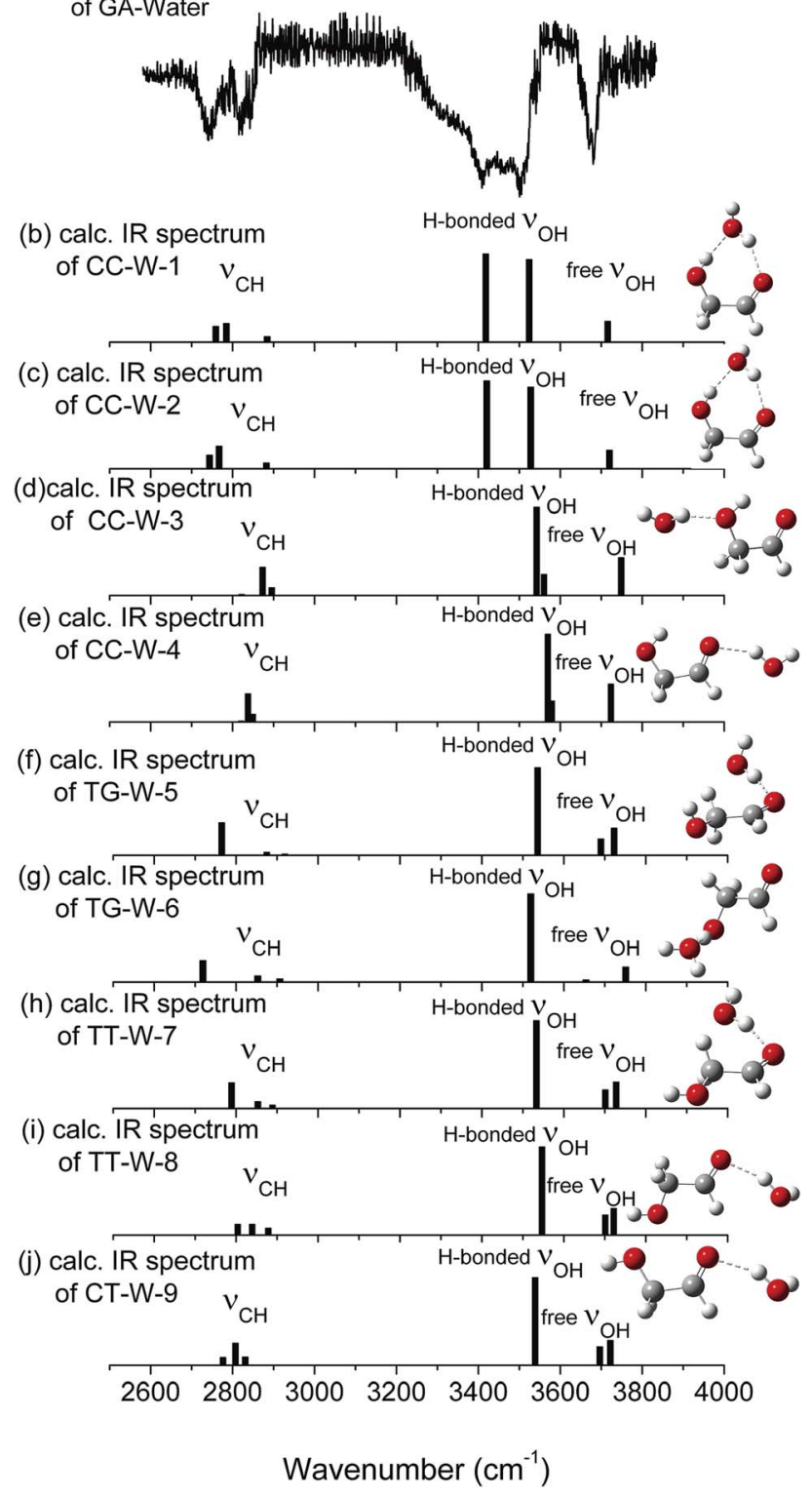

Fig. 3 (a) Observed ir spectra of GA-water and (b)-(j) $\omega B$ 97X-D/ccpVTZ calculated stick spectra of the most stable conformers of GAwater. The sticks represent $\mathrm{OH}$ and $\mathrm{CH}$ stretches. Carbon atoms are in grey, oxygen in red, and hydrogen in white. The calculated vibrational spectra are scaled by 0.9415 .

stretch $(9 \mathrm{O}-11 \mathrm{H})$, one intermolecular $\mathrm{H}$-bonded $\mathrm{O}-\mathrm{H}$ stretch $(8 \mathrm{O}-10 \mathrm{H})$, and one intermolecular $\mathrm{H}$-bonded $\mathrm{O}-\mathrm{H}$ stretch $(7 \mathrm{H}-$ 9O). In isomer CC-W-3 [Fig. 3(d)], one $\mathrm{OH}$ group of water is just $\mathrm{H}$-bonded to the oxygen of the hydroxyl group, while the CC conformer keeps the intramolecular H-bond. In isomer CC-W-4 [Fig. 3(e)], however, water is H-bonded to the carbonyl group as an H-bond donor, while the CC conformer also keeps the intramolecular $\mathrm{H}$-bond. The next five isomer, i.e., TG-W-5 [Fig. 3(f)], TG-W-6 [Fig. 3(g)], TT-W-7 [Fig. 3(h)], TT-W-8 [Fig. 3(i)], and CT-W-9 [Fig. 3(j)], have one intermolecular $\mathrm{H}^{-}$ bonded $\mathrm{O}-\mathrm{H}$ stretch and two free $\mathrm{O}-\mathrm{H}$ stretch respectively. The observed spectrum clearly shows three intense features in 
the $\mathrm{OH}$ stretch regions. One slightly sharp feature centered at $3700.5 \mathrm{~cm}^{-1}$ is assigned to the free $\mathrm{OH}$ stretch vibration, which is similar to the free $\mathrm{OH}$ stretch of the anti and gauche ethanol. ${ }^{55}$ The other two intense feature peaks, centered at around 3442.1 and $3529.0 \mathrm{~cm}^{-1}$, are red shifted by 258.4 and $171.5 \mathrm{~cm}^{-1}$, respectively, compared with the above free $\mathrm{OH}$ stretch peak. The band shifts of the $\mathrm{OH}$ stretching modes indicate that $\mathrm{OH}$ group is strongly perturbed by the hydrogen bonding interactions. This hydrogen bonding can also be verified from the increased intensity and line-width broadening (although power saturation of the vibrational transitions as well as fluctuations of the IR power source, may obscure these effects). ${ }^{20}$ However, it is unclear whether these red shifted peaks were influenced by the intramolecular hydrogen bonding or by the intermolecular interaction.

The calculated vibrational patterns and band positions of the two lowest energy conformations (CC-W-1 and CC-W-2) are both in good agreement with the experimental IR signature. Thus, the identities and structures of the CC-W-1 and CC-W-2 conformers in the neutral GA-water complexes could be confirmed. In the above conformers, the water molecule chooses the water-binding sites to form an intermolecular $\mathrm{H}$-bonded bridge, which changes the orientation of the hydroxyl group. This was similar to the previous report for hydrated monosaccharides. ${ }^{1}$ In addition, the features, which relate to weak intermolecular and intramolecular H-bonds in the CC-W-3 and CC-W-4 conformers, are close to the peaks centered at 3529.0 $\mathrm{cm}^{-1}$ in the observed spectrum. This may explain why the relative intensity of the experimental characteristic peaks centered at $3529.0 \mathrm{~cm}^{-1}$ is slightly higher than those centered at $3442.1 \mathrm{~cm}^{-1} .^{56}$ Therefore, the CC-W-3 and CC-W-4 conformers cannot be excluded in the neutral GA-water. The spectra of the next five high energy conformers aren't consistent with the observed spectrum in the $\mathrm{OH}$ region obviously. Therefore, these high energy conformers wouldn't exist in the beam of neutral
GA-water, which confirms that only CC conformer exist in the molecular beam. Table 3 reports the frequencies of the experimental bands and the calculated vibrational transitions of the four most stable conformers in accord with experimental results. The calculated anharmonic frequencies are also richer in the $\mathrm{CH}$ regions due to the presence of multiple peaks associated with transitions to overtones and combination bands. Except for the usual bandshift, the harmonic frequencies differ less from its anharmonic counterpart in higher energy range. When anharmonic corrections are included, the calculated anharmonic frequencies get more close to the experimental position compared with harmonic frequencies. Additionally, Boltzmann distribution of the hydrated GA conformers based on the relative Gibbs free energy were calculated and shown in ESI. $\dagger$ From the table, it can be seen that the CC-W-1 and CC-W-2 conformers were the main dominant contributions (about 87.6\%) while CC-W-3 and CC-W-4 conformers accounted for $12.3 \%$ in the gas phase. This implies that the probability of CC$\mathrm{W}-1$ and CC-W-2 existing is higher than those of CC-W-3 and CC-W-4. These results established that the water prefers to play the role of a bridge through hydrogen bonding rather than cooperativity, thus leading to a generalization of the rules for conformational selectivity in hydrated GA.

\subsection{Interaction energy obtained from natural bond orbital (NBO) analysis}

To substantiate the spectroscopy results and estimate the interaction strength, the stabilization energy gained from the hydrogen bond interaction was calculated at the level of $\omega \mathrm{B} 97 \mathrm{X}$ D/cc-pVTZ for the hydrated complexes. ${ }^{57}$ Fig. 4 shows $3 \mathrm{D}$ overlap diagrams for the $n_{\mathrm{S}} \rightarrow \sigma^{*}{ }_{\mathrm{OH}}$ donor-acceptor interaction energy obtained from natural bond orbital (NBO) analysis for the four stable hydrated complexes. ${ }^{58}$ For each conformer, the more orbital overlap the $n_{\mathrm{S}} \rightarrow \sigma^{*}$ OH donor-acceptor interaction obtained, the greater the magnitude of stabilization energy. The

Table 3 The experimental value and calculated vibrational transitions $\left(\mathrm{cm}^{-1}\right)$ for the four lowest-energy monohydrated GA conformers with the $\omega B 97 X-D / c c-p V T Z$ level

\begin{tabular}{|c|c|c|c|c|c|}
\hline \multirow[b]{2}{*}{ Description } & \multicolumn{3}{|c|}{ Experiment } & \multicolumn{2}{|l|}{ Calculations } \\
\hline & Observed & CC-W-1 (ha/anha) & CC-W-2 (ha/anha) & CC-W-3 (ha/anha) & CC-W-4 (ha/anha) \\
\hline Free OH stretch & 3700.5 & $3715.8 / 3683.6$ & $3720.0 / 3701.5$ & $3748.6 / 3714.2$ & $3723.5 / 3702.8$ \\
\hline H-b. OH stretch & 3529.0 & $3523.9 / 3519.2$ & $3527.6 / 3519.4$ & $3560.0 / 3550.4$ & 3579.1/3549.1 \\
\hline H-b. OH stretch & 3442.1 & $3418.1 / 3416.1$ & $3420.4 / 3411.9$ & $3542.2 / 3534.1$ & $3569.6 / 3542.3$ \\
\hline as. $\mathrm{CH}_{2}$ stretch & 2905.7 & $2884.4 / 2869.9$ & $2882.7 / 2879.4$ & $2895.6 / 2888.3$ & $2849.5 / 2843.2$ \\
\hline $\mathrm{CH}_{2}$ twist and $\mathrm{CH}_{2}$ wag, ip $\mathrm{OH}$ bend & & /2603.8 & $/ 2605.6$ & $/ 2611.2$ & $/ 2613.5$ \\
\hline $\mathrm{CH}_{2}$ twist and ip $\mathrm{OH}$ bend, $\mathrm{CH}_{2}$ wag & & $/ 2543.1$ & $/ 2541.7$ & $/ 2550.8$ & $/ 2548.4$ \\
\hline The first overtone of $\mathrm{CH}_{2}$ scissor & & $/ 2874.2$ & $/ 2869.8$ & /2880.9 & $/ 2879.3$ \\
\hline $\mathrm{CH}_{2}$ wag, ip $\mathrm{OH}$ bend and $\mathrm{CH}_{2}$ scissor & & $/ 2780.1$ & $/ 2780.3$ & /2772.6 & $/ 2773.5$ \\
\hline s. $\mathrm{CH}_{2}$ stretch & 2870.9 & $2784.9 / 2772.3$ & $2767.2 / 2759.3$ & 2873.1/2868.4 & $2837.6 / 2829.3$ \\
\hline $\begin{array}{l}\text { The first overtone of } \mathrm{CH}_{2} \text { rock and ip } \mathrm{CH} \\
\text { bend }\end{array}$ & & $/ 2700.2$ & $/ 2698.4$ & $/ 2692.8$ & $/ 2691.9$ \\
\hline $\begin{array}{l}\text { ip } \mathrm{OH} \text { bend, } \mathrm{CH}_{2} \text { wag and } \mathrm{CH}_{2} \text { wag, ip } \\
\mathrm{OH} \text { bend }\end{array}$ & & $/ 2623.8$ & /2624.1 & /2631.4 & $/ 2630.3$ \\
\hline $\mathrm{CH}$ stretch & 2801.4 & $2759.1 / 2756.1$ & $2743.8 / 2738.3$ & $2822.0 / 2804.2$ & $2821.2 / 2803.2$ \\
\hline $\begin{array}{l}\text { The first overtone of } \mathrm{CH}_{2} \text { wag, ip OH } \\
\text { bend }\end{array}$ & & $/ 2820.8$ & $/ 2919.7$ & $/ 2835.8$ & /2838.4 \\
\hline $\mathrm{CH}_{2}$ wag, ip $\mathrm{OH}$ bend and ip $\mathrm{CH}$ bend & & /2692.6 & /2689.9 & $/ 2705.3$ & $/ 2704.8$ \\
\hline
\end{tabular}




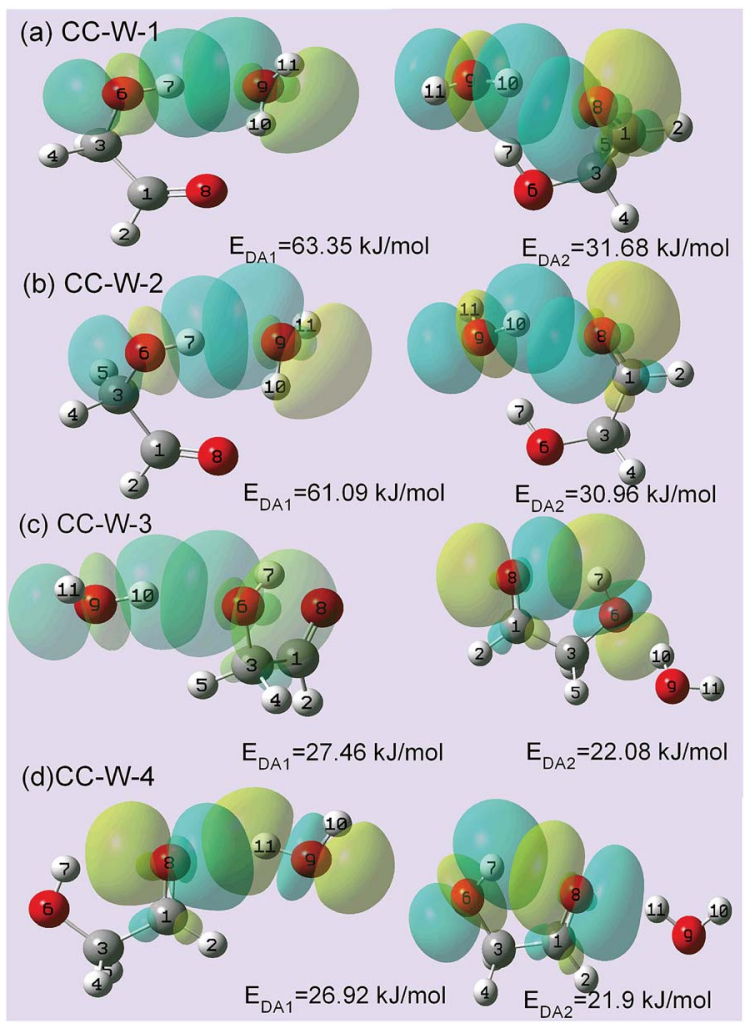

Fig. 4 NBO 3D overlap diagrams for $n_{\mathrm{S}} \rightarrow \sigma^{*}{ }_{\mathrm{OH}}$ donor-acceptor interaction in calculated GA-water conformers. EDA represents the interaction energy between the lone pair (LP) electrons/ $\pi$ electrons of $\mathrm{H}$-bond acceptors and the antibonding $\sigma_{\mathrm{O}-\mathrm{H}}$ orbital $\left(\sigma^{*}{ }_{\mathrm{O}-\mathrm{H}}\right)$ of $\mathrm{H}$ bond donors. Conformer interaction energies are shown in the figure. The NBO calculation was performed at the $\omega$ B97X-D/cc-pVTZ level of theory and basis set. All energies are in $\mathrm{kJ} \mathrm{mol}^{-1}$.

magnitude of the stabilization energy for the $6 \mathrm{O}-7 \mathrm{H} \cdots 9 \mathrm{O}$ hydrogen bond interaction is more than twice as large as for the $9 \mathrm{O}-10 \mathrm{H} \cdots 8 \mathrm{O}$ interaction in both CC-W-1 and CC-W-2 conformers. This result is consistent with the experimentally observed redshifts. ${ }^{59}$ However, the magnitude of the stabilization energy of the intermolecular $\mathrm{H}$-bonded interaction is found to be close to that of the intramolecular H-bond in both CC-W-3 and CC-W-4 conformers. Moreover, this stabilization energy is slightly lower than that of $9 \mathrm{O}-10 \mathrm{H} \cdots 8 \mathrm{O}$ in the CC-W-1 and CC$\mathrm{W}-2$ conformers. Therefore, the stretch modes related to the latter three H-bonds mentioned above would have similar vibrational frequencies and their bands would overlap in the observed spectra at $c a .3529 .0 \mathrm{~cm}^{-1}$.

\section{Conclusions}

In conclusion, mass selected IR-VUV spectroscopy has been used to directly detect the isolated and hydrated conformers of GA. The results reveal that the CC conformer with a ring-type structure is the dominant conformer in the gas-phase for neutral GA. Although all four hydrated GA conformers (labeled CC-W-1, CC-W-2, CC-W-3, and CC-W-4 in this work) could coexist in the gas phase, water molecules preferentially insert into the intramolecular hydrogen bond to form a cyclic $\mathrm{H}$ bonding bridge between the carbonyl and hydroxyl groups of the open CC conformers of GA (CC-W-1 and CC-W-2) by two additional intermolecular H-bonds. Structural investigation of hydrated GA conformers has revealed that water plays the role of a bridge through intermolecular $\mathrm{H}$-bonds, achieving selective population of specific GA molecular conformations. The conclusions drawn from the mechanisms of flexible conformation can be extended to other carbohydrates and biomolecules.

\section{Acknowledgements}

This work has been supported by NSFC (No. 11079020, 21273083, U1332132) grants and Guangdong-NSF grants (No. S2013010016551). The scientific research foundation for State Education Ministry, the foundation for introduction of talents by the universities in Guangdong Province, and the project under scientific and technological planning by Guangzhou City.

\section{References}

1 E. J. Cocinero, P. Carcabal and A. M. Rijs, Top. Curr. Chem., 2015, 364, 299-333.

2 E. C. Stanca-Kaposta, D. P. Gamblin, E. J. Cocinero, J. Frey, R. T. Kroemer, A. J. Fairbanks, B. G. Davis and J. P. Simons, J. Am. Chem. Soc., 2008, 130, 10691-10696.

3 J. B. G. Gluyas, A. N. Sobolev, E. G. Moore and P. J. Low, Organometallics, 2015, 34, 3923-3926.

4 T. D. Cook, S. N. Natoli, P. E. Fanwick and T. Ren, Organometallics, 2016, 35, 1329-1338.

5 J. Zhang, M.-X. Zhang, C.-F. Sun, M. Xu, F. Hartl, J. Yin, G.-A. Yu, L. Rao and S. H. Liu, Organometallics, 2015, 34, 3967-3978.

6 R. A. Jockusch, R. T. Kroemer, F. O. Talbot and J. P. Simons, J. Phys. Chem. A, 2003, 107, 10725-10732.

7 E. J. Cocinero, E. C. Stanca-Kaposta, E. M. Scanlan, D. P. Gamblin, B. G. Davis and J. P. Simons, Chem.-Eur. J., 2008, 14, 8947-8955.

8 J. P. Simons, B. G. Davis, E. J. Cocinero, D. P. Gamblin and E. C. Stanca-Kaposta, Tetrahedron: Asymmetry, 2009, 20, 718-722.

9 H. B. Xie, L. Jin, S. Rudic, J. P. Simons and R. B. Gerber, J. Phys. Chem. B, 2012, 116, 4851-4859.

10 L. Jin, J. P. Simons and R. B. Gerber, J. Phys. Chem. A, 2012, 116, 11088-11094.

11 N. Mayorkas, S. Rudic, E. J. Cocinero, B. G. Davis and J. P. Simons, Phys. Chem. Chem. Phys., 2011, 13, 1867118678.

12 N. Mayorkas, S. Rudić, B. G. Davis and J. P. Simons, Chem. Sci., 2011, 2, 1128-1134.

13 P. Carcabal, R. A. Jockusch, I. Hunig, L. C. Snoek, R. T. Kroemer, B. G. Davis, D. P. Gamblin, I. Compagnon, J. Oomens and J. P. Simons, J. Am. Chem. Soc., 2005, 127, 11414-11425.

14 H. S. P. Müller, F. Schlöder, J. Stutzki and G. Winnewisser, J. Mol. Struct., 2005, 742, 215-227. 
15 J. M. Hollis, F. J. Lovas and P. R. Jewell, Astrophys. J., 2000, 540, 107-110.

16 J. K. Jorgensen, C. Favre, S. E. Bisschop, T. L. Bourke, E. F. van Dishoeck and M. Schmalzl, Astrophys. J., Lett., 2012, 757, 4-9.

17 W. Stumm and J. J. Morgan, Aquatic Chemistry, Chemical Equilibria and Rates in Natural Waters, Wiley, New York, 3rd edn, 1996.

18 P. M. Wiggins, Microbiol. Mol. Biol. Rev., 1990, 54, 432-449.

19 M. Zhou, L. Andrews and C. W. Bauschlicher, Chem. Rev., 2001, 101, 1931-1962.

20 J. M. Lisy, J. Chem. Phys., 2006, 125, 132302-132320.

21 M. P. Gaigeot and R. Spezia, Top. Curr. Chem., 2015, 364, 99151.

22 A. M. Rijs and J. Oomens, Top. Curr. Chem., 2015, 364, 1-42. 23 Y. J. Hu, J. W. Guan and E. R. Bernstein, Mass Spectrom. Rev., 2013, 32, 484-501.

24 C. Y. Ng, M. A. Johnson and T. J. Martinez, Annu. Rev. Phys. Chem., 2014, 65, 197-224.

25 T. S. Zwier, Annu. Rev. Phys. Chem., 1996, 47, 205-241.

26 T. Ebata, A. Fujii and N. Mikami, Int. Rev. Phys. Chem., 1998, 17, 331-361.

27 U. Buck and F. Huisken, Chem. Rev., 2000, 100, 3863-3890. 28 M. A. Duncan, Int. Rev. Phys. Chem., 2003, 22, 407-435.

29 J. M. Lisy, J. Chem. Phys., 2006, 125, 132302.

30 H. Niki, P. D. Maker, C. M. Savage and L. P. Breitenbach, Chem. Phys. Lett., 1981, 80, 499-503.

31 A. Aspiala, J. Murto and P. Sten, Chem. Phys., 1986, 106, 399412.

32 J. Ceponkus, W. Chin, M. Chevalier, M. Broquier, A. Limongi and C. Crepin, J. Chem. Phys., 2010, 133, 094502-094506.

33 J. R. Aviles-Moreno, J. Demaison and T. R. Huet, J. Am. Chem. Soc., 2006, 128, 10467-10473.

34 Y. J. Hu, H. B. Fu and E. R. Bernstein, J. Chem. Phys., 2006, 125, 154306.

35 Y. J. Hu, H. B. Fu and E. R. Bernstein, J. Phys. Chem. A, 2006, 110, 2629-2633.

36 Y. J. Hu, H. B. Fu and E. R. Bernstein, J. Chem. Phys., 2006, 125, 154305.

37 H. B. Fu, Y. J. Hu and E. R. Bernstein, J. Chem. Phys., 2006, 124, 024302.

38 Y. J. Hu, H. B. Fu and E. R. Bernstein, J. Chem. Phys., 2006, 124, 114305.

39 S. Maity, R. I. Kaiser and B. M. Jones, Faraday Discuss., 2014, 168, 485-516.

40 M. J. Frisch, G. W. Trucks, H. B. Schlegel, G. E. Scuseria, M. A. Robb, J. R. Cheeseman, J. A. Montgomery Jr, T. Vreven, K. N. Kudin, J. C. Burant, J. M. Millam, S. S. Iyengar, J. Tomasi, V. Barone, B. Mennucci, M. Cossi, G. Scalmani, N. Rega, G. A. Petersson, H. Nakatsuji, M. Hada, M. Ehara, K. Toyota, R. Fukuda, J. Hasegawa, M. Ishida, T. Nakajima, Y. Honda, O. Kitao, H. Nakai, M. Klene, X. Li, J. E. Knox, H. P. Hratchian, J. B. Cross, V. Bakken, C. Adamo, J. Jaramillo, R. Gomperts, R. E. Stratmann, O. Yazyev, A. J. Austin, R. Cammi, C. Pomelli, J. W. Ochterski, P. Y. Ayala, K. Morokuma, G. A. Voth, P. Salvador, J. J. Dannenberg, V. G. Zakrzewski,
S. Dapprich, A. D. Daniels, M. C. Strain, O. Farkas, D. K. Malick, A. D. Rabuck, K. Raghavachari, J. B. Foresman, J. V. Ortiz, Q. Cui, A. G. Baboul, S. Clifford, J. Cioslowski, B. B. Stefanov, G. Liu, A. Liashenko, P. Piskorz, I. Komaromi, R. L. Martin, D. J. Fox, T. Keith, M. A. Al-Laham, C. Y. Peng, A. Nanayakkara, M. Challacombe, P. M. W. Gill, B. Johnson, W. Chen, M. W. Wong, C. Gonzalez and J. A. Pople, Gaussian 03, Revision C.02, Gaussian, Inc., Wallingford CT, 2004.

41 M. J. Frisch, G. W. Trucks, H. B. Schlegel, G. E. Scuseria, M. A. Robb, J. R. Cheeseman, G. Scalmani, V. Barone, B. Mennucci, G. A. Petersson, H. Nakatsuji, M. Caricato, X. Li, H. P. Hratchian, A. F. Izmaylov, J. Bloino, G. Zheng, J. L. Sonnenberg, M. Hada, M. Ehara, K. Toyota, R. Fukuda, J. Hasegawa, M. Ishida, T. Nakajima, Y. Honda, O. Kitao, H. Nakai, T. Vreven, J. A. Montgomery Jr, J. E. Peralta, F. Ogliaro, M. Bearpark, J. J. Heyd, E. Brothers, K. N. Kudin, V. N. Staroverov, R. Kobayashi, J. Normand, K. Raghavachari, A. Rendell, J. C. Burant, S. S. Iyengar, J. Tomasi, M. Cossi, N. Rega, J. M. Millam, M. Klene, J. E. Knox, J. B. Cross, V. Bakken, C. Adamo, J. Jaramillo, R. Gomperts, R. E. Stratmann, O. Yazyev, A. J. Austin, R. Cammi, C. Pomelli, J. W. Ochterski, R. L. Martin, K. Morokuma, V. G. Zakrzewski, G. A. Voth, P. Salvador, J. J. Dannenberg, S. Dapprich, A. D. Daniels, Ö. Farkas, J. B. Foresman, J. V. Ortiz, J. Cioslowski and D. J. Fox, Gaussian 09, revision $C$ 01, Gaussian, Inc., Wallingford CT, 2009.

42 R. N. Pribble and T. S. Zwier, Science, 1994, 265, 75-79.

43 K. Sakota, M. Schütz, M. Schmies, R. Moritz, A. Bouchet, T. Ikeda, Y. Kouno, H. Sekiya and O. Dopfer, Phys. Chem. Chem. Phys., 2014, 16, 3798.

44 M. Schütz, K. Sakota, R. Moritz, M. Schmies, T. Ikeda, H. Sekiya and O. Dopfer, J. Phys. Chem. A, 2015, 119(39), 10035-10051.

45 B. L. Yoder, K. B. Bravaya, A. Bodi, A. H. C. West, B. Sztáray and R. Signorell, J. Chem. Phys., 2015, 142, 114303.

46 Y. K. Kang and B. J. Byun, Biopolymers, 2012, 97, 778-788.

47 A. Kinal and S. Sayhan, Int. J. Hydrogen Energy, 2016, 41, 392400.

48 M. Xie, Y. Matsuda and A. Fujii, J. Phys. Chem. A, 2015, 119, 5668-5675.

49 M. L. Senent, J. Phys. Chem. A, 2004, 108, 6286-6293.

50 Y. Matsuda, K. Hoki, S. Maeda, K. I. Hanaue, K. Ohta, K. Morokuma, et al., Phys. Chem. Chem. Phys., 2012, 14, 712-719.

51 J.-W. Shin and E. R. Bernstein, J. Chem. Phys., 2009, 130, 214306.

52 P. Carbonniere and C. Pouchan, Theor. Chem. Acc., 2012, 131, 1183.

53 M. Jetzki, D. Luckhaus and R. Signorell, Can. J. Chem., 2004, $82,915$.

54 J. Ceponkus, W. Chin, M. Chevalier, M. Broquier, A. Limongi and C. Crepin, J. Chem. Phys., 2010, 133, 094502.

55 Y. J. Hu, H. B. Fu and E. R. Bernstein, J. Chem. Phys., 2006, 125, 154305-154310. 
56 T. N. Wassermann, P. Zielke, J. J. Lee, C. Cezard and M. A. Suhm, J. Phys. Chem. A, 2007, 111, 7437-7448.

57 S. D. Schroder, J. H. Wallberg, J. A. Kroll, Z. Maroun, V. Vaida and H. G. Kjaergaard, J. Phys. Chem. A, 2015, 119, 9692-9702.
58 E. D. Glendening, C. R. Landis and F. Weinhold, Adv. Rev., 2012, 2, 1-42.

59 V. R. Mundlapati, S. Ghosh, A. Bhattacherjee, P. Tiwari and H. S. Biswal, J. Phys. Chem. Lett., 2015, 6, 1385-1389. 